\title{
Las bibliotecas públicas peruanas frente a la crisis de la COVID-19: servicios, reflexiones y desafíos*
}

Resumen

La inesperada expansión del nuevo coronavirus o COVID-19, al inicio del 2020, ha causado efectos alarmantes en todo el mundo, provocando la suspensión de diversas actividades económicas y sociales, entre ellas, los servicios bibliotecarios. Las bibliotecas públicas tuvieron que cerrar sus locales al decretarse el estado de emergencia en sus países y entrar en un periodo de confinamiento. Este panorama ha generado el extensivo uso de los servicios digitales en las bibliotecas para continuar laborando, hecho que se expone en este trabajo. Además, se indican algunas posturas de especialistas del ámbito bibliotecario latinoamericano con respecto a la situación actual. En el presente estudio se obtiene como resultado una problemática extendida en la que se indica que las bibliotecas públicas del Perú trabajan de "modo presencial" con limitados recursos, escaso personal especializado, ausencia de servicios digitales y sin visibilidad dentro de sus gobiernos locales; a pesar de esto, algunas bibliotecas han desarrollado diversas iniciativas en medio de esta pandemia. Por tanto, se muestra una serie de servicios que están brindando las bibliotecas públicas peruanas en respuesta a la crisis de la COVID-19; también se indican algunas reflexiones del ámbito bibliotecario del país y una serie de desafíos para un futuro próximo.

Palabras clave: bibliotecas públicas, servicios bibliotecarios, servicios digitales, COVID-19, crisis sanitaria, pandemia, Perú.

Cómo citar este artículo: Quispe-Farfán, Gabriela (2020). Las bibliotecas públicas peruanas frente a la crisis de la COVID-19: servicios, reflexiones y desafíos. Revista Interamericana de Bibliotecología, 43(3), eRf2. https://doi.org/10.17533/udea.rib.v43n3eRf2

Recibido: 2020-06-20 / Aceptado: 2020-07-22

\section{Gabriela A. Quispe-Farfán}

Doctora en Documentación de la Universidad Carlos III de Madrid, España. Máster en Sistemas de Información Digital de la Universidad de Salamanca, España. Bibliotecóloga de la Universidad Nacional Mayor de San Marcos, Perú. 100334140@alumnos.uc3m.es https://orcid.org/0000-0001-8547-7251
* Este texto resulta de la coyuntura actual que se vive en el mundo a causa de la crisis sanitaria por la COVID-19; en él también se presenta parte de los resultados de la tesis doctoral "Innovación tecnológica en bibliotecas públicas municipales de Lima: un estudio exploratorio, diagnóstico y propuesta de líneas estratégicas”, Universidad Carlos III de Madrid, 2020. 


\section{Peruvian Public Libraries in the Face of the COVID-19 Crisis: Services, Reflections and Challenges}

\begin{abstract}
The unexpected expansion of the new coronavirus or COVID-19, at the beginning of 2020, has caused alarming effects throughout the world, causing the suspension of various economic and social activities, including library services. Public libraries had to close their premises when the state of emergency was decreed in their countries and entered a period of confinement. This panorama has generated the extensive use of digital services in libraries to continue working, a fact that will be exposed in this work. In addition, some statements by specialists in the Latin American library sphere regarding the current situation are indicated. In the present study, an extended problem is obtained where it is indicated that the public libraries of Peru work "face-toface" with limited resources, scarce specialized personnel, absence of digital services, and no visibility within their local governments. Despite this, some libraries have carried out various initiatives in the midst of this pandemic. Therefore, a series of services that Peruvian public libraries are providing in response to the COVID-19 crisis are shown, as well as some reflections from the library sphere in the country and a series of challenges for the near future.
\end{abstract}

Keywords: Public libraries, library services, digital services, COVID-19, health crisis, pandemic, Peru.

\section{Introducción}

El mundo ha sido testigo de una nueva pandemia en el siglo XXI. El ll de junio del 2009, la Organización Mundial de la Salud (OMS) declaró la primera pandemia con la gripe $\mathrm{HINl}$ (mal llamada gripe porcina) causada por una variante de la influenza A (Banegas \& Mejía, 2010). En el 2020, la COVID-19, también declarada pandemia, está causando estragos en casi todos los países: detiene las actividades de todo tipo y obliga a los gobiernos a decretar estados de emergencias y a imponer el confinamiento para evitar su propagación. Esto significa el cierre de instituciones como las bibliotecas públicas.

Las bibliotecas, al ser lugares públicos y de interacción social, han tenido que cerrar sus puertas de manera temporal hasta que el virus sea contenido. Ante esto, la respuesta inmediata en gran parte de las bibliotecas es brindar servicios digitales, como las plataformas de libros y videos, las aplicaciones móviles, los audiolibros, las redes sociales y la referencia virtual. De forma creativa, se empezaron a desarrollar servicios que se adapten a las necesidades de los usuarios y se ha recurrido al uso del teléfono y al préstamo de libros en físico considerando las medidas de seguridad sanitaria. También se han realizado algunas reuniones virtuales de especialistas del ámbito bibliotecario, para conocer sus opiniones y recomendaciones frente a la situación de confinamiento y distanciamiento social.

En el caso peruano, por lo general, las bibliotecas brindan servicios presenciales y desarrollan colecciones físicas, con diversas limitaciones, como el reducido apoyo de los gobiernos, el escaso personal especializado y la falta de tecnologías en sus servicios. Esta realidad se refleja en casi todas las bibliotecas de la región latinoamericana. La COVID-19 ha provocado la aceleración de la virtualización en las actividades; por tanto, algunas bibliotecas del ámbito nacional, con denodados esfuerzos, han logrado implementar servicios y productos digitales para sus comunidades durante este confinamiento. Ante este panorama, este trabajo presenta algunas iniciativas brindadas por las bibliotecas peruanas ante la crisis sanitaria, con algunas reflexiones sobre la situación presente, y los desafíos a los que se enfrentan de cara al futuro, en un contexto pospandemia.

\section{Una crisis inesperada: la reacción de las bibliotecas en un contexto de aislamiento obligatorio}

El 30 de diciembre del 2019, el comité sanitario municipal de Wuhan informó sobre 27 casos de pacientes con una "neumonía inexplicable" (Deutsche Welle, 2019). Esto aconteció en la provincia de Hubei, parte central de China, una de las zonas más afectadas por este nuevo virus, denominado un tiempo después como SARS-CoV-2 y el cual produce la enfermedad del coronavirus o COVID-19. ${ }^{1}$

1 La OMS declaró el 11 de febrero del 2020 el nombre del nuevo virus: Coronavirus disease COVID19, denominado anteriormente de forma temporal 2019nCoV disease. Véase el tweet: https:/ twitter.com/WHO/status/1227248333871173632 
El 11 de marzo del 2020, la OMS la declaró una pandemia. Llegó a América en enero y para fines de mayo del 2020 esta región ya era el epicentro de la enfermedad (Infomediatico, 2020).

A comienzos del año, en América del Sur aún se escuchaban las noticias del nuevo virus con la sensación de bastante lejanía, hasta que, el 25 de febrero del 2020, se registró el primer caso de coronavirus en la región, en São Paulo, Brasil. El 6 de marzo se confirmó el primer paciente de coronavirus en Lima, Perú, ${ }^{2}$ lo que causó las primeras alarmas en la población. El 15 de marzo, el Gobierno peruano, mediante Decreto Supremo N. ${ }^{\circ}$ 044-2020-PCM, declaró el estado de emergencia nacional y aislamiento social obligatorio a causa de la COVID-19, en vigor desde las 0 horas del 16 de marzo. ${ }^{3}$ Pero, a pesar de tomar medidas tempranas y de decretar más ampliaciones, para principios de junio Perú sería uno de los diez países más afectados a nivel mundial. ${ }^{4}$

Varios países alrededor del mundo empezaron a decretar el estado de emergencia o alarma: se cerraron instituciones, universidades, escuelas, centros comerciales, parques, etc.; aunque se permitió la movilidad de trabajadores imprescindibles del sector salud, transporte, seguridad y alimentación, y se recomendó el teletrabajo. En Perú, las medidas llegaron con el Decreto de Urgencia N. ${ }^{\circ}$ 026-2020, para prevenir la propagación del virus en el país, con el aislamiento obligatorio de más de treinta millones de personas en el territorio, el cierre de sus fronteras y la paralización de la actividad económica.

La Federación Internacional de Asociaciones de Bibliotecarios y Bibliotecas (IFLA, por sus siglas en inglés) informó, a través de su sección web "COVID-19 y el Sector Bibliotecario Global", que casi la totalidad de las bibliotecas públicas en el mundo cerraron sus puertas de manera temporal hasta empezar el desconfinamiento (véase Figura 1). Se suspendieron las actividades y los servicios presenciales, se empezó a brindar servicios por medios digitales, se ampliaron

2 Véase en el siguiente enlace https://bit.ly/3hmSltY

3 Decreto Supremo N. ${ }^{\circ}$ 044-2020-PCM: https://bit.ly/2YoV4sT

4 Información en tiempo real en https://www.worldometers.info/ coronavirus/ las fechas de préstamo y se suspendieron las multas. En el lado europeo, la mayoría de las bibliotecas cerraron al público hasta nuevo aviso, aunque conservaron los servicios y contenidos digitales, incentivando el teletrabajo para los bibliotecarios y brindando información sobre la COVID-19 a través de sus webs institucionales. Algunos ejemplos son los servicios ofrecidos por las bibliotecas de Finlandia, donde se ofrece el uso de plataformas de libros electrónicos, audiolibros, películas y base de datos, sobre los cuales se ha incrementado el número de préstamos de recursos electrónicos, ha pasado de 5 a 20 préstamos. En España, se resalta el acceso a los recursos por medio de e-Biblio (préstamo de libros electrónicos) y eFilm (plataforma de préstamos audiovisuales en streaming). La Biblioteca Nacional de Polonia provee más de tres millones de recursos a sus ciudadanos a través de su biblioteca digital (https://polona.pl/), son cerca de cien mil libros y novecientas mil revistas, la mayoría se pueden descargar en PDF y la red de bibliotecas públicas portuguesas está subiendo recursos y enlaces de sus actividades a Flipboard ${ }^{5}$ (NAPLE Members, 2020).
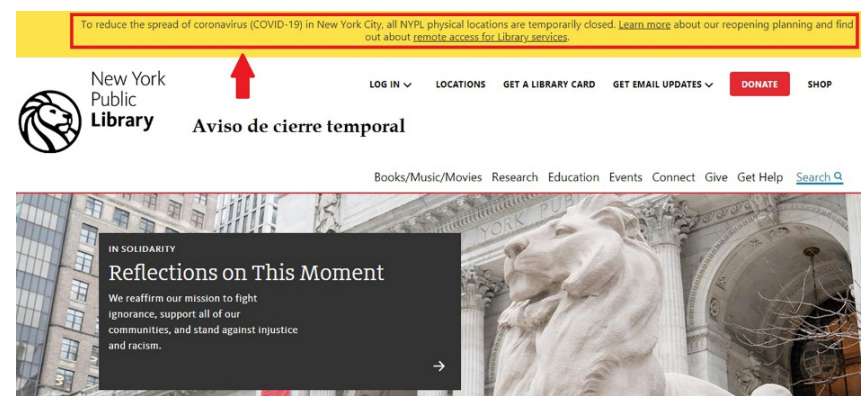

Figura 1. Aviso de cierre temporal.

Fuente: página web de la Biblioteca Pública de Nueva York.

En el caso de Suecia, el $90 \%$ de las bibliotecas se mantuvieron abiertas (IFLA, 2020a) y continuaron brindando algunos servicios alternativos, como el préstamo de material físico "drive-through" (regresar y recoger libros sin salir del auto), "take away" (recolectar libros preordenados en una bolsa en la puerta de la biblioteca a una hora específica), "book bags" (bolsas con libros seleccionados por un bibliotecario según un tema) y entrega de libros a domicilio para personas mayores de 70 años o pertenecientes a grupos de riesgo (NAPLE Members, 2020).

5 Véase https://flipboard.com/@RNBP_DGLAB 
Este tipo de servicios de recogida y devolución se replican en centros de Estados Unidos, como ocurre en la Biblioteca Pública de Alexandria, en Ohio, que ofrece recogidas en la acera (Fallows, 2020).

Cabe destacar algunas iniciativas de apoyo de las bibliotecas al personal sanitario de los hospitales, como la realizada por la Biblioteca Pública del Condado del Dorado, en California, con la producción de protectores faciales en sus laboratorios de impresión 3D. También se resalta el apoyo a personas sin hogar a partir de la adecuación de los auditorios de los centros culturales como refugios. Asimismo, los bibliotecarios participan activamente en los servicios de información a la ciudadanía desde sus ciudades de origen, como lo hace la Biblioteca Pública de Rochester en Minnesota (Morales \& Hines, 2020). La situación actual conllevó el resurgimiento de un dispositivo casi en desuso: el teléfono, este ha sido un aparato esencial en algunas bibliotecas en época de cuarentena, especialmente para las personas mayores que no dominan las tecnologías digitales. En Colorado, siete bibliotecas del condado de Adams atienden llamadas de usuarios para hablar de lo que piensan o simplemente para saludar (Fallows, 2020). En Lituania se brinda el servicio de lectura del libro para los adultos mayores, quienes eligen el título para que el personal de la biblioteca lo lea por medio del teléfono (NAPLE Members, 2020).

En Latinoamérica, nos encontramos con diversas iniciativas para enfrentar el confinamiento y continuar con las labores. Asimismo, se han desarrollado foros virtuales, conversatorios y seminarios en línea sobre el contexto actual de la COVID-19 y las bibliotecas. Una de estas iniciativas fue el Foro Virtual “ \#BibliotecasEnCasa ¿Cómo las bibliotecas pueden extender sus servicios durante las cuarentenas?", realizado el 21 de marzo del 2020, organizado por IFLA en conjunto con el Colegio Colombiano de Bibliotecología (Ascolbi) e Infotecarios. ${ }^{6}$ En este foro, varios especialistas del ámbito bibliotecario expusieron ideas clave para el progreso de las bibliotecas. Dentro de las conclusiones, se recomienda la extensión de los servicios y contenidos digitales de calidad dirigida a los ciudadanos con previo conocimiento de las necesidades reales de los usuarios; del mismo modo, se mencionó la ca-

6 Véase en el canal de IFLA (2020c): https://bit.ly/3feDdvh pacidad de adaptación del bibliotecario al contexto actual para asumir nuevos retos y desarrollar servicios con innovación, creatividad e imaginación. La alfabetización informacional es esencial en esta época para enfrentar la infodemia; ${ }^{7}$ por tanto, las bibliotecas deben desarrollar guías y recursos informativos confiables sobre la COVID-19. Se resalta la labor de las bibliotecas que unen esfuerzos con otras instituciones o colectivos y toman su labor social de forma consciente y transformadora para hacer frente a la crisis; estas además reafirman el mensaje "Yo me quedo en casa" y enfatizan en que la unión de todos los actores que participan en el ámbito bibliotecario "hace a la biblioteca" (Firmas Invitadas, 2020).

Otro evento interesante fue el conversatorio "Bibliotecas y Comunidad en el contexto del Aislamiento Social Preventivo. Imaginando el futuro", organizado por la Oficina Regional para América Latina y el Caribe de IFLA, ${ }^{8}$ emitido por el Facebook de la Biblioteca del Congreso el 27 de mayo del 2020. En este evento se presentaron las siguientes reflexiones sobre la inesperada crisis y cómo las bibliotecas deben trabajar.

- Las bibliotecas se encuentran ante nuevos retos y tienen una visión global, pero se desenvuelven en distintas realidades. En América Latina se prevé una profunda crisis económica y desigualdad social, informacional y digital. Por tanto, se debe tener un diagnóstico de la situación local y aunar esfuerzos con todos los involucrados para desarrollar estrategias.

- Los servicios públicos se revalorizan, especialmente, en países en los que se han revelado carencias en los servicios sanitarios públicos; lo que da a entender que lo público y la acción colectiva para el bien co-

7 Es la excesiva información falsa o con un bajo nivel de credibilidad, que se propaga rápidamente.

8 Con la participación de la Lic. Glória Pérez-Salmerón, expresidenta de la IFLA y actual presidenta de Stichting IFLA Global Libraries Foundation; María Angélica Fuentes Martínez, jefa del Comité Permanente de la Sección América Latina y el Caribe de la IFLA y coordinadora del Área de Recursos Digitales de la Biblioteca del Congreso de Chile; Alejandro Lorenzo César Santa, director-coordinador general de la Biblioteca del Congreso de la Nación de Argentina; e Isela Mo Amavet, gerente regional de la Oficina Regional para América Latina y el Caribe de la IFLA, en el siguiente enlace https://bit.ly/37smxxN 
mún es imprescindible para gestionar la actual crisis sanitaria. Esto ha visibilizado la importancia de las instituciones públicas, entre ellas, las bibliotecas. Por un lado, debe haber más inclusión para personas con habilidades especiales, con limitaciones físicas y para personas que no cuentan con los medios para acceder a tecnologías e información de calidad y, por otro, las bibliotecas deben utilizar indicadores para saber si se alcanzan las metas y objetivos trazados para el desarrollo de sus sociedades.

- Se apuesta por la reinvención de la profesión en relación con el rol social y político, y esta crisis es una gran oportunidad para hacerlo. Por ello, los bibliotecarios, como los profesionales que dirigen las políticas públicas de la información, tienen que ser autocríticos con la labor que han estado realizando en estos últimos años, deben involucrarse aún más con sus comunidades y responder eficazmente a las nuevas necesidades de información de nuestros tiempos; de igual manera, deben conocer la realidad de sus países y afianzarse para enfrentar situaciones futuras.

- Las bibliotecas deben ser espacios de construcción ciudadana y deben centrarse en la alfabetización informacional; de esta manera, las personas desarrollan sus habilidades y capacidades para su desarrollo y pueden combatir la infodemia, que fácilmente se expande en internet y en las redes sociales.

- Además, las bibliotecas deben apostar por la cooperación, la participación y por compartir las experiencias y el saber.

Las bibliotecas públicas de Latinoamérica, por lo general, son presenciales, con colecciones físicas y con locales en los que se ofrecen los servicios y actividades. Con la crisis sanitaria, se dio el cierre total de los sistemas bibliotecarios públicos. Las prontas acciones para implementar sus servicios se trasladaron al mundo digital; el uso de las redes sociales tales como Facebook, Instagram o Twitter ha sido amplio, y estas redes se han convertido en las mejores vías para comunicarse con sus usuarios. Un ejemplo sobre esto es el informe "Bibliotecas argentinas ante el aislamiento social y obligatorio por el COVID-19", cuyos resultados indican que un $47,5 \%$ de las bibliotecas utilizan un perfil en redes sociales, el 36,7\% realiza el servicio de referencia por medio de estas y un $35,4 \%$ por medio de WhatsApp (Gutierrez \& Castaño, 2020). Además, se ha incrementado el número de visitas a las páginas web y al catálogo de búsqueda; también ha aumentado el consumo de contenidos digitales como libros, audiolibros, visualización de películas, clubes de lectura virtuales, entre otros. Sin embargo, un número importante de bibliotecas públicas simplemente cerraron sus puertas, no brindan ningún servicio y están a la espera del desconfinamiento.

Es así como las bibliotecas de la región se enfrentan a los nuevos retos del siglo XXI ante lo inusitado del suceso, una pandemia para la que nadie estuvo preparado y una crisis sanitaria que se extenderá por unos años más. Por tanto, las bibliotecas deben fortalecer su rol social y adaptarse a los nuevos cambios, para seguir siendo un eje transformador y activo, tanto en un espacio físico como virtual. Así lo indica Anglada (2014), en un probable escenario del año 2030: "si la generación actual de bibliotecarios no es capaz de introducir cambios radicales en el papel de las bibliotecas, su continuidad está seriamente amenazada” (p. 603).

\section{Situación de las bibliotecas públicas de Perú en medio de la crisis del coro- navirus}

El Gobierno peruano, dirigido por el presidente Martín Vizcarra, adoptó medidas sin precedentes: abrió la caja fiscal y entregó bonos para hogares pobres, para trabajadores independientes, para la micro y pequeña empresa; asimismo, permitió el retiro de la compensación por tiempos de servicios (CTS) y el retiro de los fondos privados de pensiones para las personas desempleadas. Estas acciones se realizaron para mitigar los problemas económicos de la ciudadanía. A pesar de esto y transcurridos casi tres meses de instaurada la medida de emergencia, se hace insostenible la situación debido a las limitaciones del Estado, tales como la informalidad, la precariedad de la sanidad pública, el restringido acceso a la educación pública, la corrupción, la brecha social y digital, el ruido político y otros problemas. Una de las consecuencias de estas calamidades ha sido el alto índice de desempleo - según el Instituto Nacional de Estadística e Informática 
(INEI), se cuenta con una tasa del 9,0\% en el primer trimestre del 2020-, por lo cual una gran cantidad de personas tienen que salir a las calles para buscar el sustento y, al no tomar medidas de bioseguridad, se ha incrementado el número de contagios. Para la primera semana de junio, cuando se escribía este artículo, se contaba con más de doscientos mil casos y más de seis mil decesos por la COVID-19.

Perú está denominado como un país en "vía de desarrollo"; antes de la pandemia, la inversión en educación $(3,72 \%$ del PBI) y en ciencia y tecnología $(\mathrm{I}+\mathrm{D}+\mathrm{i})$ (solo el 0,08\% del PBI) era muy limitada, con el agravante de contar con bajos o moderados indicadores de desarrollo, tanto en el empleo como en la salud, los servicios básicos y la tecnología; esto se muestra en la siguiente tabla (Tabla 1).

Con este panorama, el país se enfrenta la crisis sanitaria y la próxima crisis económica, lo que profundiza la brecha social, el aumento del desempleo y la creciente informalidad. Asimismo, estas dificultades afectan directamente a las bibliotecas públicas porque en gran parte son financiadas con dinero público y se enfrentaran a recortes presupuestales. Según el Registro Nacional de Municipalidades (INEI-RENAMU) (2019), se cuenta con 477 bibliotecas públicas municipales, lo que representa una de las coberturas más bajas de la década, con un $25,45 \%$ a nivel nacional.

Tabla 1. Indicadores generales, Perú.

\begin{tabular}{|c|c|c|c|}
\hline Indicadores & Perú & Indicadores & Perú \\
\hline IDH (2018) & 0,759 & PBI per cápita & S/. 23561,00 \\
\hline Esperanza de Vida (2020) & 76,5 años & Inversión I+D+i (2016) & $0,08 \%$ del PBI \\
\hline Cobertura de Seguro de Salud (2020) & $76,50 \%$ & Tasa de alfabetización (2018) & 94,41 \\
\hline Hogares c/ agua potable (2020) & $67,70 \%$ & Gasto público en educación (2018) & $3,72 \%$ del PBI \\
\hline Hogares con Internet & $29,80 \%$ & Población en pobreza monetaria (2019) & $20,20 \%$ \\
\hline Idiomas (2017) & $\begin{array}{c}\text { castellano }(82,94 \%) \text {, quechua }(13,6 \%) \text {, } \\
\text { aymara }(1,61 \%) \text {, ashaninka }(0,26 \%), \\
\text { aguaruna }(0,20 \%) \text { y otras lenguas } \\
\text { extranjeras }(0,15 \%)\end{array}$ & $\begin{array}{l}\text { Cobertura de bibliotecas públicas } \\
\text { municipales a Nivel Nacional (2018) }\end{array}$ & $25,45 \%$ \\
\hline
\end{tabular}

Fuente: Datosmacro (2020a, 2020b, 2020c), INEI (2018, 2020), INEI-RENAMU (2019), Programa de las Naciones Unidas para el Desarrollo (PNUD) (2019), Redacción Gestión (2018, 2020).

De estas, solo cinco regiones cuentan con una cobertura igual o superior al $50 \%$ : Callao $(71,43 \%)$, Tumbes $(69,23 \%)$, Piura (66,15 \%), Apurímac $(55,95 \%)$ y Lambayeque (50 \%). Las regiones Madre de Dios (9,09\%), Ayacucho (8,4\%), Amazonas (7,14\%) y Tacna (con $0 \%$ ) son las que tienen menos cobertura en el país. Perú tiene una densidad bibliotecaria de 1,62 bibliotecas por cada 100000 habitantes, muy por debajo de Brasil $(2,91)$, Chile $(2,77)$, Colombia $(3,43)$ y Uruguay $(1,83)$, como lo indica la Tabla 2.

Sumado a esta realidad está la baja asistencia de los peruanos a las bibliotecas públicas que se ha dado progresivamente en la última década. El total de usuarios atendidos en las bibliotecas públicas fue de 1393033 y, de estos, 1073452 hicieron uso de las salas de lectura que solo disponen de 17208 puestos de lectura a nivel nacional (INEI-RENAMU, 2019). Por ello, se calculan 0,05 usuarios por habitante y 0,59 puestos de lectura por 1000 habitantes. Estos indicadores revelan la escasa visibilidad de las bibliotecas en la sociedad; al no contar con un número suficiente de bibliotecas y puestos de lecturas, la asistencia es mínima.

La biblioteca pública en el Perú, desde su creación, ha tenido una historia inestable, nació con la República y está a punto de cumplir 200 años de labor. Durante las últimas décadas, el desarrollo de las bibliotecas ha tenido dificultades y éxitos efímeros, en los que aparecen bibliotecas en un gran número con ánimos de llevar cultura a las comunidades, pero, una vez que les reducen los presupuestos y caen en el olvido por parte de las autoridades, estas desparecen. 
Tabla 2. Densidad bibliotecaria de las bibliotecas públicas de América del Sur.

\begin{tabular}{lccccc}
\hline Países & Bibliotecas públicas & Año & Población & Año & Densidad bibliotecaria \\
\hline Perú & 477 & 2019 & 29381884 & 2017 & 1,62 \\
Argentina & 30 & 2017 & 44494500 & 2018 & 0,07 \\
Brasil & 6102 & 2015 & 209469300 & 2018 & 2,91 \\
Chile & 519 & 2017 & 18729200 & 2018 & 2,77 \\
Colombia & 1702 & 2016 & 49648700 & 2018 & 3,43 \\
Ecuador & 12 & 2017 & 17084400 & 2018 & 2,07 \\
Paraguay & 93 & 2019 & 6956100 & 2018 & 1,34 \\
Uruguay & 63 & 2018 & 3449300 & 2018 & 1,83 \\
Venezuela & 0 & 0 & 28870200 & 2018 & 0 \\
Bolivia & N/D & N/D & 11353100 & 2018 & N/D \\
\hline
\end{tabular}

Nota: densidad Bibliotecaria $=(N$. de Bibliotecas * 100 000) $/$ Población. N/D=No hay datos.

Fuente: Google y Banco Mundial (2020), IFLA (2020b), INEI (2018), INEI-RENAMU (2019).

Este mecanismo de "aparecer y desaparecer" de las bibliotecas se viene manteniendo por años, a vista y paciencia de gobiernos locales, regionales y del gobierno central, por más que se den elocuentes discursos de la importancia del libro y la lectura.

El Sistema Nacional de Bibliotecas (SNB) fue creado por la Ley N. 30034 como instrumento de gestión pública para propiciar el funcionamiento y eficiencia de las bibliotecas, y para garantizar la calidad y acceso de los servicios bibliotecarios, mas no para desarrollar y crear bibliotecas, solo es funcional y con una participación pasiva, lo que da a las autoridades locales esa potestad de creación. Hasta el momento, se han emprendido capacitaciones en las bibliotecas, pero esto es insuficiente al contar con un limitado número de profesionales en bibliotecología que dirijan estos centros; según INEI-RENAMU (2019), solo se cuenta con 363 profesionales en bibliotecología a nivel nacional en los puestos de las bibliotecas públicas municipales. La mayoría de los que dirigen las bibliotecas, por lo general, son personal administrativo, de confianza partidaria, temporal y con un nivel básico de estudio. Por tanto, el desarrollo de las bibliotecas hacia una modernización está estancada profundamente por factores políticos.

En relación con los servicios, los más extendidos son el servicio de lectura en sala, 93,3\%; el préstamo a domicilio, 53,0 \%; y los servicios culturales, 45,7 \%. El 41,7\% cuenta con una sala infantil. Los que escasamente están incluidos son el servicio de internet, con un $36,3 \%$; el catálogo de acceso público, con un $21,6 \%$; y la biblioteca itinerante, con un $11,5 \%$. Respecto a la colección, el número de ejemplares es de 1591739 , lo que representa el 88,5 \% de la colección a nivel nacional (0,05 libros por habitante), de estos, 13801 ejemplares son material audiovisual y 3694 ejemplares son libros electrónicos, es decir, un índice de 0,47 documentos audiovisuales por 1000 habitantes y 1,26 documentos electrónicos por 10000 habitantes, respectivamente (INEI-RENAMU, 2019). Esto demuestra los recursos limitados en colección y servicios.

Si bien hay buenas iniciativas para la promoción del libro y la lectura por parte de las bibliotecas, como sucedió con la experiencia de la "Meta 27 y la Meta 06", estas se quedan en buenas intenciones. El funcionamiento de la mayoría de las bibliotecas sigue la línea de depósito de libros y espacios de trabajo de los municipios, con horarios limitados, con una colección desactualizada y escolarizada, mínima oferta de servicios digitales, sin contar con redes de bibliotecas consolidadas y poco inclusivas. Por consiguiente, es necesario implementar estrategias dirigidas por el $\mathrm{SNB}$, con un marco legal renovado, con personal comprometido y especializado, con fondos económicos propios, con su inclusión en las políticas públicas de

9 La Meta 27 (2015) y la Meta 06 (2017) fueron metas promocionadas por el "Programa de Incentivos a la Mejora de la Gestión Municipal” (PI) por la Ley N.o 29332 y modificatorias del Ministerio de Economía y Finanzas (MEF). Este mecanismo público tenía como objetivo impulsar los planes de lectura en los municipios a través de sus bibliotecas y transferir recursos por metas cumplidas en un determinado tiempo. 
la agenda nacional y, sobre todo, es necesario buscar visibilizarse en la estructura del Estado. "La falta de visibilidad de la biblioteca pública constituye el mayor problema para su desarrollo" (Suaiden, 2018, p. 1139). Ahora, con más razón, se necesitan los centros bibliotecarios para que el ciudadano pueda acceder a información fiable y eficaz, para enfrentar las consecuencias de esta crisis sanitaria sin precedentes.

\section{Servicios implementados en las biblio- tecas públicas peruanas para afrontar el confinamiento}

Ahora bien, ¿cómo se está trabajando en época de confinamiento en el país? Una vez establecida la inmovilización social, la Biblioteca Nacional del Perú (BNP) y las bibliotecas públicas tuvieron que cerrar sus puertas para salvaguardar a los usuarios y trabajadores de posibles contagios. Esta situación se repitió en diversos países, que han tenido que desarrollar otro tipo de actividades para seguir en funcionamiento en épocas de la COVID-19; asimismo, se realizan planes para el regreso de las bibliotecas y las nuevas normas de salubridad en los locales bibliotecarios, planes coordinados con el sistema de sanidad de cada país y orientados a lo que sería "la nueva normalidad", un panorama pospandemia.

Perú estableció medidas económicas, pero, también, siguió con acciones para apoyar la educación del país, desde el nivel básico hasta el superior. Se dispuso las clases de forma remota, pero en el país más del 70 \% no cuenta con internet en sus hogares. Se emitió entonces el programa "Aprendo en Casa"10 con cursos para inicial, primaria, secundaria y básica especial, mediante televisión y radio de alcance nacional, incluso en otras lenguas del país distintas al castellano. Las universidades tuvieron que realizar las clases de manera virtual, apoyadas por diversas herramientas tecnológicas, como las plataformas propias de sus instituciones, el correo electrónico, Zoom, WhatsApp, Facebook, Google Meet, Skype, etc. Estos programas son celebrados, pero las bibliotecas públicas, que son parte del sector cultural y de soporte del sector educación, no han sido apoyadas por las autoridades ni han sido incluidas en estos programas. Solo algunas bibliotecas que cuentan

10 Estos son los horarios de los cursos: https://bit.ly/3hgBGGZ con una página web o un perfil en las redes sociales prestan servicios de forma remota.

La BNP es una institución que tiene los recursos necesarios y que puede desarrollar fácilmente servicios digitales, pues cuenta con perfiles en las redes sociales Facebook, Instagram, Twitter y en las plataformas YouTube y Spotify; en ellas publica sus actividades con frecuencia. En esta última, se encuentran los podcasts sobre del ciclo de conservatorios "Lectura, Biblioteca y Comunidad". Tiene una aplicación móvil de lectura "BNP Digital" por medio de la cual se accede a diversas publicaciones del patrimonio cultural de la nación. El servicio de consultas en línea se realiza mediante correo electrónico, bot y el servicio del referencista virtual "chatea con un bibliotecario" en un horario establecido (véase Figura 2). Realizan algunas actividades como el cinefórumBNP, charlas magistrales en historia sobre Perú, "Diálogos en tiempos de cambio", conversatorios, cuentacuentos, entre otros.

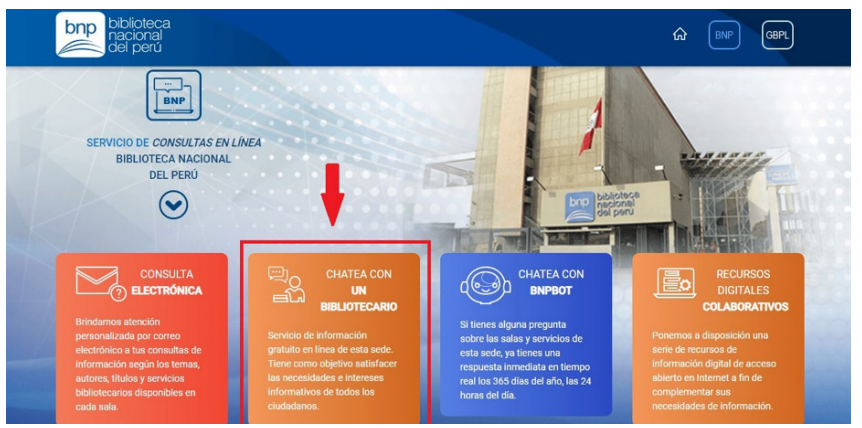

Figura 2. Servicio de chat en línea.

Fuente: Biblioteca Nacional del Perú (BNP).

La Biblioteca Municipal de Lima cuenta con página web, en ella, se encuentran los libros de cabildo y las publicaciones de munilibro para descargar. También cuentan con un nuevo servicio, "Pregúntale al bibliotecario", por medio del cual pueden enviar sus consultas bibliográficas al correo biblioteca@munlima.gob.pe. La Casa de la Literatura Peruana continúa con su club de lectura de manera virtual y realiza diversos conversatorios de contenido literario y cultural, también cuenta con el servicio de cuentacuentos narrados por personas mayores en el programa "Abuelas y Abuelos Cuentacuentos de la Casa de la Literatura Peruana” en https://bit.ly/37iPOWS. Del mismo modo, la Biblioteca Municipal de Miraflores cuenta con su "Club de lec- 
tura Julio Ramón Ribeyro" y San Borja Cultura con su "Club de lectores"; las reuniones se realizan vía Zoom. La Biblioteca Pública Municipal del Callao "Teodoro Casana Robles", con su programa "La biblioteca va a tu casa" mediante su Facebook (https://bit.ly/3e5y48A), difunde videos de poetas de la provincia narrando sus publicaciones. Asimismo, las bibliotecas comunales también están realizando algunas iniciativas, como la Biblioteca "El Manzano" del Rímac, que presenta una serie de audios sobre cuentos y biografías de peruanos reconocidos en Soundcloud: https://soundcloud.com/ user-973205394. Por otro lado, algunas bibliotecas están realizando préstamos de libros físicos, como son las bibliotecas rurales Murukushun (Ancash), la Biblioteca Comunal Carlitos Oquendo de Amat (Puno) con su servicio de "préstamos de libros por delivery", el Vagón Cultural y Ambiental de Pueblo Libre con el programa "La biblioteca va a tu casa" con 8000 títulos $^{11}$ y la Biblioteca Municipal de Barranco con 2500 títulos a disposición de los vecinos (véase Figura 3).

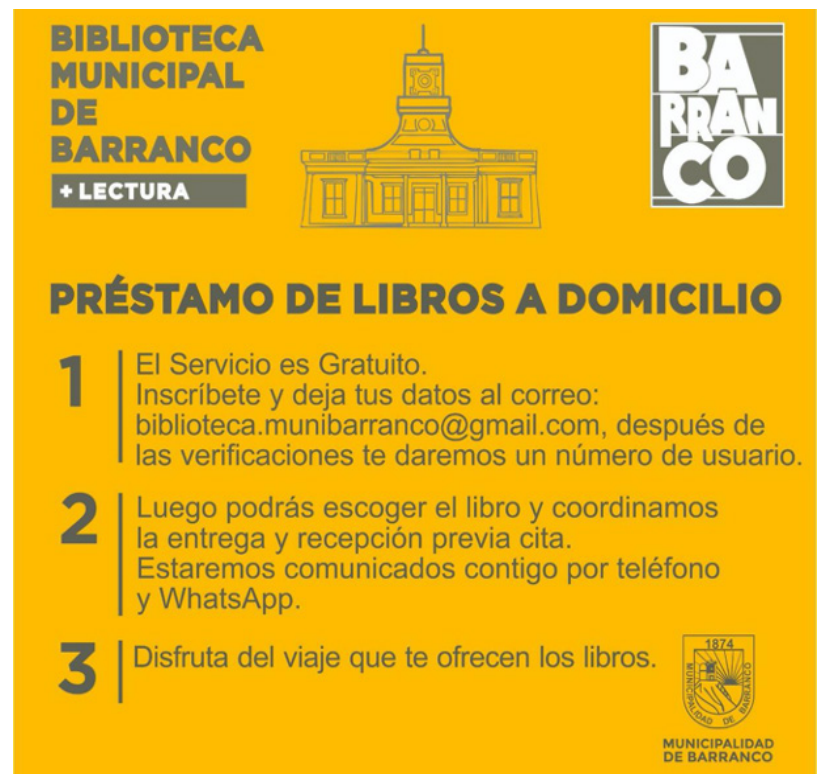

Figura 3. Servicio de préstamo de libros a domicilio en época de pandemia.

Fuente: Facebook de Barranco + Cultura.

La Biblioteca Municipal de Arequipa con su programa "Lecturas compartidas con biblioteca infantil" provee audiocuentos que son narrados por el voluntariado de la biblioteca vía Spotify en https://spoti.fi/2UzntLA,

11 Listado de libros para su préstamo: https:/muniplibre.gob.pe/ portal/biblioteca-municipal-prestamos-de-libros/
Anchor en https://bit.ly/30zG0vc y YouTube en https://bit.ly/3dRKst2. De igual manera, a través de sus redes, organiza diversos conversatorios. La Biblioteca Municipal de Cusco "Gustavo Pérez Ocampo" usa la red social de cultura del municipio para comunicar sus actividades, entre ellas, lecturas libres de derecho de autor tanto de producción nacional como internacional, también realizó por el día de la madre un reto con el \#Mimamameleyo para saber, en un video de 20 segundos, cuál fue el primer libro que les leyó la mamá. De esta manera, se valora la función mediadora de la madre hacia la lectura. La biblioteca de Piura "Ignacio Escudero" programa una serie de cuentos virtuales denominada "La magia del cuento" vía Facebook: https:// bit.ly/2YozB3b. Asimismo, la emisión de audios y videos se ha presentado tanto por medios sociales como por radio y televisión local, para llegar a más ciudadanos de la provincia. La Biblioteca Municipal de Huánuco, mediante su programa "Una biblioteca para todos", organiza presentaciones de libros de diversos autores de su comunidad por medio de su red social en https://bit. ly/3feI3Zt y cuenta con un espacio radial denominado LECTURERA- "Sin límite de páginas", transmitido por Radio Huánuco 94.7 FM como lo indica la Figura 4.

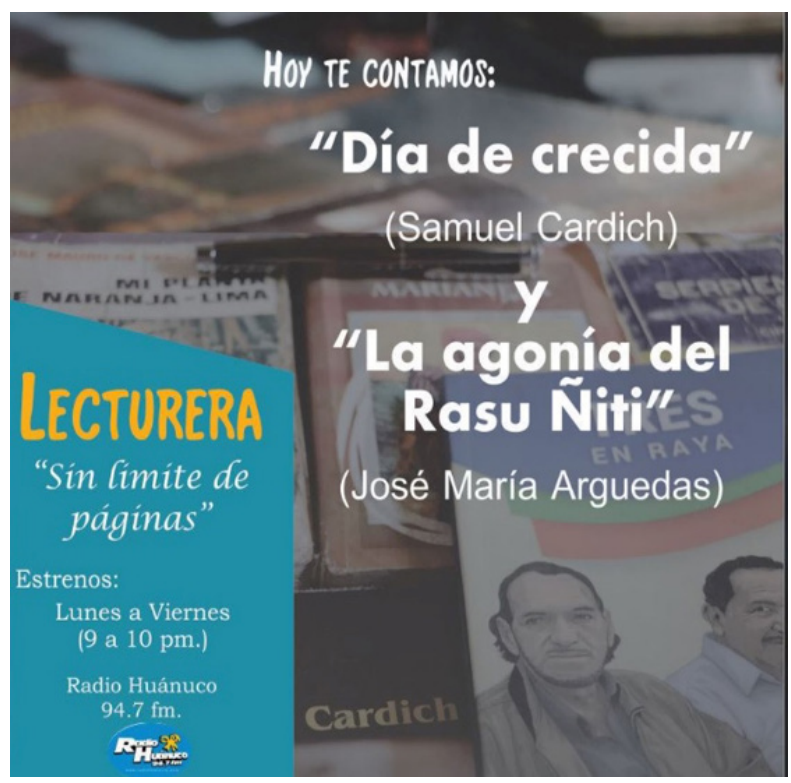

Figura 4. Programa de radio que fomenta la lectura.

Fuente: Facebook de la Biblioteca Municipal de Huánuco.

"Lima Lee" es un programa gestionado por la Municipalidad de Lima, desarrolla, a través de sus redes sociales, conferencias virtuales, recitales, conversatorios, talle- 
res, concursos, entrevistas a autores; además, cuenta con una plataforma digital "Mega Colección de Libros" en https://bit.ly/3cRU8lR (véase Figura 5), con títulos variados y de diversa temática, con el fin de incentivar la lectura - para la primera semana de junio se llegó a las veinte mil descargas - con el \#YoMeQuedoEnCasa. También está \#LimaLeeTeCuenta, por medio del cual los colaboradores narran sus libros o poemas favoritos. Otra acción de este programa, que cabe resaltar, es la instalación de doce módulos con diversos títulos dentro de las instalaciones "Casa de Todos", en la Plaza de Acho en Rímac, donde se beneficia a las personas sintecho de Lima, las cuales fueron trasladadas a este recinto a causa de la crisis sanitaria. La Red de Bibliotecas Rurales de Cajamarca trabaja los servicios de préstamo de libros físicos, por lo que se paralizaron los servicios, pero, antes de la cuarentena, se entregaron folletos de difusión sobre la COVID-19 en las comunidades.

UีMA

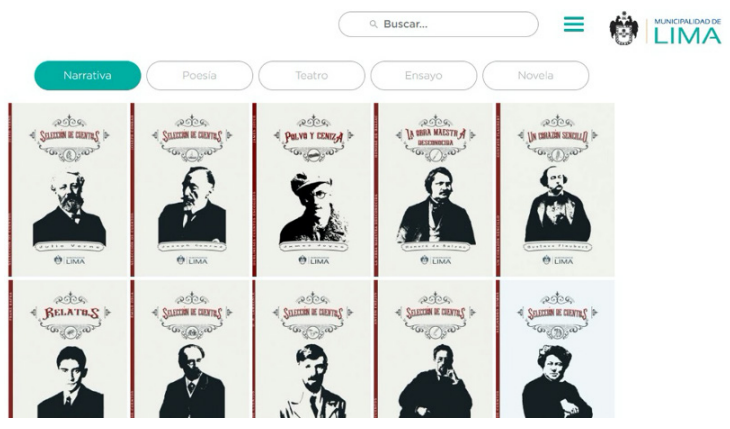

Figura 5. Plataforma de lectura digital.

Fuente: programa "Lima Lee".

Estos son algunos ejemplos en los que las bibliotecas han seguido operando. Aun así, son varias las unidades de información que carecen de recursos para poder implementar servicios que se adapten al contexto actual y a un panorama pospandemia.

\section{Algunas reflexiones y desafíos}

Nos hallamos en medio de una emergencia sanitaria que la mayoría nunca había vivido; los esfuerzos por lograr una vacuna en corto tiempo han hecho que se valore aún más el campo de la investigación científica y la sanidad pública de los países. Del mismo modo, a los otros servicios sociales como la educación y la cultura, de los cuales son parte las bibliotecas, se les está volviendo a dar el valor como elementos esenciales para el desarrollo de la persona, como motores de crecimiento de una nación. Por tanto, los gobiernos deben preocuparse por cuáles son las prioridades de sus poblaciones $y$, principalmente, qué sectores deben tener reconocimiento y mayor financiación.

Ante esta situación por la que están atravesando las bibliotecas públicas de Perú, es oportuno presentar algunas reflexiones:

a) Las bibliotecas públicas carecen de visibilidad dentro de los gobiernos locales a los que pertenecen. A pesar de que se reconocen como centros de apoyo de aprendizaje constante del ciudadano, no tienen una participación clara dentro de las políticas públicas.

b) El SNB tiene un alcance limitado para desarrollar y financiar las bibliotecas públicas en el país, por lo que deja esta labor a los gobiernos regionales y locales.

c) Las estrategias y acciones realizadas por algunas bibliotecas en este periodo se realizan sin cooperación ni colaboración con otras unidades de información. Esto ha evidenciado las escasas redes de bibliotecas y las limitadas políticas con objetivos comunes.

d) A lo largo de los años, la mayoría de los que dirigen las bibliotecas se han enfocado en las colecciones físicas, cuando las bibliotecas también pueden desenvolverse en el ámbito digital, pues también son "cultura, educación e información digital". A causa de esta reducida visión, actualmente un gran número de centros en el país continúan cerrados por la crisis.

e) Las redes sociales han sido las herramientas con mayor uso en las bibliotecas en este periodo; se ha verificado que a pesar de las dificultades han diseñado servicios de emergencia en forma remota. Esto es originado por el alto porcentaje de bibliotecas que no tienen una ventana digital como una página web, blog institucional o biblioteca digital. Pero se puede comprobar que varios municipios cuentan con páginas bien diseñadas y estructuradas.

f) Se ha realizado una gran cantidad de conversatorios, reuniones y conferencias enfocadas en el tema 
de las bibliotecas del país frente a la COVID-19; en estos han participaron especialistas, bibliotecarios y jefes de bibliotecas, dando voz al sector, exponiendo la problemática, ideas e iniciativas que están realizando en este contexto. Estas son algunas que vale la pena resaltar:

- Conversatorio virtual "Buenas prácticas en la reinversión de bibliotecas". ${ }^{12}$ Por el señor Juan Yangali y el bibliotecólogo Sandro Tucto. Realizada el 12 de junio de 2020 y organizada por el programa "Lima Lee".

- Charla Virtual "La voz de nuestras bibliotecas en las regiones: análisis y perspectivas ante el COVID-19 en nuestro Perú". ${ }^{13}$ Realizada el 03 de junio de 2020, organizada por la Asociación de Bibliotecólogos del Perú, con el \#LimaNoEsElPerú y \#HablanLasRegiones.

- Conversatorio virtual "El rol de las bibliotecas Públicas Municipales durante el distanciamiento social". ${ }^{14}$ Realizado el 22 de mayo del 2020, organizado por la BNP.

- Conferencia Virtual "Las bibliotecas públicas peruanas ante el COVID-19"15 por el bibliotecario Alan Concepción. Realizada el 15 de mayo del 2020, organizado por el programa "Lima Lee".

- Conferencia Virtual "Las bibliotecas del Perú ante el COVID-19: perspectivas y retos". ${ }^{16}$ Realizado el 15 de abril del 2020, por la Asociación de Bibliotecólogos del Perú y la Universidad Nacional Tecnológica de Lima Sur.

Ciertamente, la labor del bibliotecario se tiene que fortalecer ante los nuevos retos del presente y los que vendrán. Algunas consecuencias inmediatas son la aceleración de la virtualización de los servicios bibliotecarios, el teletrabajo y la adaptación de novedosas

12 Se puede ver en el siguiente enlace https://bit.ly/2B3bKxU

13 Se emitió por https://bit.ly/3cUNdzl

14 En este evento se dio la participación de Ezio Neyra (jefe institucional de la BNP), véase en https://bit.ly/3fjwZu3

15 Véase en el siguiente enlace https://bit.ly/30EMF74

16 Véase en el siguiente enlace https://bit.ly/37juntC herramientas tecnológicas (ej. inteligencia artificial, internet de las cosas, realidad virtual o aumentada, etc.). Por ello, algunos desafíos que afrontan las bibliotecas son los siguientes:

a) La reinvención de la biblioteca. Deben estar dirigidas por personal especializado y calificado, con experiencia en tomas de decisiones, y, sobre todo, deben contar con personal creativo, que cultive la cultura de la innovación (Fino-Garzón, 2018; Riaza, 2014). Además, deben trabajar en redes locales, asociarse con otras instituciones, contar con independencia financiera, diseñar objetivos y metas en común, y participar activamente en la política pública de sus regiones.

b) La cultura digital. El personal tiene que manejar los medios tecnológicos, diseñar servicios virtuales y semipresenciales. Es inconcebible pensar un futuro sin la presencia de herramientas tecnológicas y sin el mundo virtual.

c) Estudio de las necesidades de su comunidad. Uno de los grandes problemas es no conocer a la comunidad a la que se sirve, es esencial saber cuáles son las necesidades y habilidades que poseen los usuarios. De esta manera, se pueden diseñar servicios y productos adaptados.

d) Alfabetización informacional. Es necesario instruir a la comunidad en habilidades de búsqueda de información fiable y enseñarles cómo discriminar la información que ronda en las redes sociales e internet. Esto se ha visto en el contexto actual; fácilmente se han compartido por medios sociales (Facebook, Twitter, Instagram y WhatsApp) videos y mensajes virales de información falsa de la COVID-19.

e) Reapertura de las bibliotecas. Trabajo y comunicación en conjunto sobre la seguridad sanitaria para el inicio de las labores. Por el momento, se cuenta con las disposiciones de la Resolución Directoral N. 02 -2020-BNP-J-DDPB (26/05/2020) de la BNP, con los "Criterios orientadores para el progresivo reinicio de los servicios bibliotecarios". ${ }^{17}$

17 Criterios recomendados en este enlace https://bit.ly/3dV2OJF 


\section{Conclusiones}

Estamos ante una pandemia, con un virus que aún se propaga en Latinoamérica, y las políticas públicas de los gobiernos se han dirigido a salvaguardar la salud por encima de la economía, aunque se prevé una crisis económica. En medio de esta coyuntura y frente a la magnitud de lo que se vive, y lo que se vivirá, se tiene que redimensionar el nuevo rol de las bibliotecas de aquí en adelante. Las respuestas de las bibliotecas alrededor del mundo han sido variadas; en la región latinoamericana, la gran mayoría de bibliotecas ofrecen servicios de manera presencial, por ello, se ha comprobado un incremento de servicios en el ámbito virtual al cerrar los locales bibliotecarios. Pero en Europa y América del Norte no ha supuesto demasiado esfuerzo brindar servicios digitales, porque ya contaban con dichas prestaciones y la infraestructura tecnológica necesaria.

La crisis sanitaria llegó en una situación desfavorable para el país. Perú tiene un 20,2% de su población bajo el umbral de pobreza y sin servicios como el agua potable y la sanidad; asimismo, solo el 29,80 \% de los hogares cuenta con internet. La inversión en educación y en I+D+i es reducida, con un 3,72\% del PBI y el 0,08\% del PBI, respectivamente. La cobertura de las bibliotecas públicas en el territorio es del $25,45 \%$, con un alto porcentaje en servicios presenciales y una escasa oferta de productos y prestaciones digitales; cuentan con limitados recursos económicos, con un escaso número de profesionales de la información que las dirijan y con una reducida visibilidad dentro de sus instituciones, de las que en última instancia dependen.

Las bibliotecas públicas peruanas implementan sus servicios de forma particular y no colectiva, porque hay una ausencia de redes de bibliotecas. Las iniciativas dispuestas en este periodo son loables porque, a pesar de las deficiencias de sus centros, han desarrollado servicios creativos e interesantes para seguir atendiendo a sus comunidades. Esta crisis no solo ha evidenciado problemas, sino también los diferentes esfuerzos que están haciendo las bibliotecas para desarrollar servicios de emergencia apoyados por el entorno digital. Las grandes protagonistas han sido las redes sociales, que han servido de canales para transmitir información y acceso a contenidos como audiocuentos, videos de narraciones, reuniones de especialistas y plataformas digitales de lectura; también han permitido interactuar e incentivar la participación de sus usuarios. Además, una alternativa para personas que carecen de dispositivos tecnológicos e internet es el préstamo de libros físicos con todos los protocolos de seguridad brindados por algunas bibliotecas.

La actual circunstancia ha de hacernos reflexionar sobre qué acciones tomar para un futuro próximo. Es pertinente pasar a la acción de manera rápida y coordinada hacia una etapa de modernización de las bibliotecas públicas basada en la cultura de la innovación, sobre todo, de cambios radicales. Esta es una gran oportunidad para revalorar y reinventar las bibliotecas, y dar a conocer cuán necesarias son estas ante situaciones como las que se viven en este momento, es decir, situar a las bibliotecas como ejes del desarrollo, de apoyo a la educación e intermediarias del conocimiento y la cultura. Un diagnóstico situacional de las bibliotecas es vital para diseñar mejores estrategias y enfrentar los desafíos producidos por esta crisis. A través de la unión de esfuerzos de los involucrados en el ámbito bibliotecario y la voluntad política, se puede dar inicio a una nueva historia de la biblioteca peruana, para que este no sea un "eterno proceso de reinvención", sino una "reinvención efectiva”.

\section{Referencias}

1. Anglada, Lluís (2014). ¿Son las bibliotecas sostenibles en un mundo de información libre, digital y en red? El Profesional de la Información 23(6), 603-61l. https://doi.org/10.3145/epi.2014.nov.07

2. Banegas, Oscar; Mejía, Norma (2010). La primera pandemia del siglo XXI. Infección por virus de influenza A (HINl). Acta Pediátrica Hondureña, l(1), 37-41 http://www.bvs.hn/APH/pdf/APHVoll/pdf/APHVoll-1-2010-9.pdf

3. Biblioteca del Congreso (2020, 27 de mayo). Conversatorio. Bibliotecas y Comunidad en el contexto del Aislamiento Social Preventivo. Imaginando el futuro [Archivo de video de Facebook]. https://www.facebook.com/ watch/live/?v=896734647478332\&eref=watch_permalink

4. Congreso de la República de Perú (19 de marzo de 2009). Ley que crea el plan de incentivos a la mejora de la gestión municipal. [Ley N. ${ }^{\circ}$ 29332]. Diario Oficial El 
Peruano, Normas Legales. Lima. http://www.leyes.congreso.gob.pe/Documentos/Leyes/29332.pdf

5. Congreso de la República de Perú (15 de mayo de 2013). Ley del Sistema Nacional de Bibliotecas. [Ley N.30034]. Diario Oficial El Peruano, Normas Legales. Lima. https:// busquedas.elperuano.pe/normaslegales/ley-del-sistema-nacional-de-bibliotecas-ley-n-30034-946195-1/

6. Datosmacro (2020a). Perú - Gasto público Educación. https://datosmacro.expansion.com/estado/gasto/educacion/peru

7. Datosmacro (2020b). Perú - Gasto público Salud. https://datosmacro.expansion.com/estado/gasto/salud/ peru

8. Datosmacro (2020c). Perú - Tasa de alfabetización. https:/datosmacro.expansion.com/demografia/tasa-alfabetizacion/peru

9. Deutsche Welle (2019, 31 de diciembre). Funcionarios chinos investigan la causa del brote de neumonía en Wuhan. Deutsche Welle. https://p.dw.com/p/3VXV1

10. Fallows, Deborah (2020, 12 de mayo). The Post-pandemic Future of Libraries. The Atlantic. https://www.theatlantic.com/notes/2020/05/post-pandemic-future-libraries/611458/

11. Fino-Garzón, Diego (2018). Catálogo para la innovación en bibliotecas públicas. Bogotá: CERLALC; Fundación Germán Sanchez Ruiperez. https://cerlalc.org/wp-content/ uploads/2018/09/Cat\%C3\%Allogo-para-la-innovaci\%C3\%B3n-en-bibliotecas-p\%C3\%BAblicas.pdf

12. Firmas Invitadas (2020, 03 de marzo). Conclusiones del Foro Virtual \#BibliotecasEnCasa ¿Cómo las bibliotecas pueden extender sus servicios durante las cuarentenas? Infotecarios. https://www.infotecarios.com/ conclusiones-del-foro-virtual-bibliotecasencasa-como-las-bibliotecas-pueden-extender-sus-servicios-durante-las-cuarentenas/\#.XtvbflUzbDc

13. Google; Banco Mundial (2020). Public Data. Población. https://bit.ly/30xC3H7

14. Gutierrez, Fernando; Castaño, Jessica (2020). Informe: Bibliotecas argentinas ante el aislamiento social y obligatorio por el COVID-19. https://drive.google.com/file/d/1WsOVrhHN9FthypDNCzjgc9GINabspqpr/view
15. IFLA (2020a). COVID-19 y el Sector Bibliotecario Global. https://www.ifla.org/ES/node/92983

16. IFLA (2020b). IFLA Library Map of the World. https://librarymap.ifla.org/map/Metric/Physical-Visits/ LibraryType/National-Libraries,Academic-Libraries,Public-Libraries,Community-Libraries,School-Libraries, Other-Libraries/Country/Peru/Weight/Totals-by-Country

17. IFLA (2020c). ¿Cómo las bibliotecas pueden extender sus servicios durante las cuarentenas? [Archivo de video]. https://www.youtube.com/watch?v=3ovn5x3SacY

18. INEI (2018). Censos nacionales 2017. XII de población, VII de vivienda y III de comunidades indígenas - REDATAM [Base de datos]. https://censos2017.inei.gob.pe/redatam/

19. INEI (2020). Perú en cifras. https://www.inei.gob.pe/

20. INEI-RENAMU (2019). Microdatos [Base de datos]. http://iinei.inei.gob.pe/microdatos/

21. Infomediatico (2020, 28 de mayo). A medida que América se convierte en el "epicentro" del coronavirus. ¿Cuáles son los países más afectados y qué están haciendo para frenar la pandemia? Infomediatico. https://www. infomediatico.com/2020/05/28/a-medida-que-americase-convierte-en-el-epicentro-del-coronavirus-cualesson-los-paises-mas-afectados-y-que-estan-haciendopara-frenar-la-pandemia/

22. Morales, Macey; Hines, Shawnda (2020, 09 de abril). Public libraries launch, expand services during COVID-19 Pandemic. ALA News. http://www.ala.org/news/ press-releases/2020/04/public-libraries-launch-expand-services-during-covid-19-pandemic-0

23. NAPLE Members (2020). Public Libraries in Europe and COVID-19: Findings from NAPLE Members, April 2020. https://www.culturaydeporte.gob.es/ dam/jcr:fce29eal-1b83-479b-b674-a592b255f7e4/ naple-narrative-report---european-library-services-during-covid19.pdf

24. Presidencia de la República de Perú (15 de marzo de 2020). Decreto Supremo que declara Estado de Emergencia Nacional por las graves circunstancias que afectan la vida de la Nación a consecuencia del brote del COVID-19. [Decreto Supremo N. 0 044-2020-PCM]. Diario Oficial El Peruano, Normas Legales. Lima. https://busquedas.elperuano.pe/normaslegales/decreto-supremo-que-declara-estado-de-emergencia-nacional-po-decreto-supremo-n-044-2020-pcm-1864948-2/ 
25. Presidencia de la República de Perú. (15 de marzo de 2020). Decreto de urgencia que establece diversas medidas excepcionales y temporales para prevenir la propagación del coronavirus (COVID-19) en el territorio nacional. [Decreto Urgencia Nº 026-2020]. Diario Oficial El Peruano, Normas Legales. Lima. https://busquedas.elperuano.pe/normaslegales/decreto-de-urgencia-que-establece-diversas-medidas-excepcion-decreto-de-urgencia-n-026-2020-1864948-1/

26. PNUD (2019). Panorama general Informe sobre Desarrollo Humano 2019. Más allá del ingreso, más allá de los promedios, más allá del presente - Desigualdades del desarrollo humano en el siglo XXI. http://hdr.undp.org/ sites/default/files/hdr_2019_overview__spanish.pdf

27. Redacción Gestión (2018, 16 de enero). Comex Perú: I+D+i, un incentivo que aún no despega. Gestión. https:// gestion.pe/economia/empresas/comex-peru-i-d-i-incentivo-despega-224992-noticial

28. Redacción Gestión (2020, 20 de mayo). Pobreza en Perú bajó el 2019 pero subió el nivel de la pobreza extrema. Gestión. https://gestion.pe/peru/nivel-de-pobreza-en-peru-se-redujo-ligeramente-en-el-2019-noticia/

29. Riaza, Maribel (2014). Innovación en Bibliotecas. Barcelona: $\mathrm{UOC}$

30. Suaiden, Emir-José (2018). La biblioteca pública y las competencias del siglo XXI. El Profesional de la Información, 27(5), 1136-1144. https://doi.org/10.3145/epi.2018.sep.17 